\title{
Format-Operation Type-Ecology
}

\section{The New Approach of the Trend and Development Pattern of Animation "Field Design"}

\author{
Qiao Zeng \\ Academy of Arts \& Design \\ Tsinghua University \\ Beijing, China \\ e-mail: zengqiao010@163.com
}

\begin{abstract}
Based on the traditional dualism approach of "format (art)-operation type (business)", this paper introduces a three-stage development pattern of "format-operation typeecology". This idea was inspired by the fact that the design orientation of animation has changed from the simple and single "object design" to the complex and comprehensive "field design", the compound of many animation designs of film and television, derivatives design, theme park and game design, etc. Animation products are finished during the "format" period of animation field. By grafting with business operation and activities, the animation industry is established by interaction of "format" and business activities, and thus we entered into the "operation type" phase of animation field. Most current animation designs stay in this phase. In the end, this paper gives the outlook of the possibility and necessity for operation type stage to develope into the ecology stage. The visual effects of format period and the economic goals of operation type period is no longer the standard of outstanding animation, while the goal of co-existing with human takes the place. The ecology stage, against nearsighted visual stimulation, advocates the communication and integration with human values. Based on this, the animation design is becoming an autologous haematopoietic entity and a huge field filled with vitality, comprising and absorbing like a huge sponge. It can get the long last vitality by audiences' recognition and its evolution. Instead of unsustainable design derived from pop culture, it's a new development approach for the upgrade from "format-operation type" to "ecology" of animation design and should be taken into consideration.
\end{abstract}

Keywords-animation; field; format-operation typeecology; development pattern

\section{THE RESEARCH BACKGROUND OF THE UPGRADING FROM DURISM TO THREE-STAGE}

Art creation and industry development are the two basic ways of addressing the problems proposed by animation development. Actually, art creation is dealing with the format aspect of animation, and the industry development with operation type aspect of animation. The "format-operation type" approach was the classic pattern of animation development before. But the widespread of media players and the soaring growth of informationalized terminal products changed this. The art brand of animation accelerated the process of its globalization, strategic development and systematization. The trend of resources integration and ecology orientation is taking shape. The mere factor of "excellent art creation ability of animation" or "strong promotion, operation and management ability of animation" can not realize the complete success of the animation art. Also, the curiosity-driven "premium era" by simply adding the two factors together has come to the end. The new background and animation development are questioning the traditional dualism approach sharply.

As the new information media of film and television, the splendid animations feature in the following two ways: first, it's a system that comprises and integrates resources of other domains, not a simple entity; second, it's distinguished by interaction. It is kept alive by repeated utilization and further development of animation originality, by the improvement of its autologous haematopoietic ability and the sustainable development of the originality resources.

Therefore, based on traditional dualism approach of "format-operation type" and by way of the research methods of communication studies, this paper brings into the threestage approach of "format-operation type-ecology". Ecology is an extension of "format-operation type" stage. The three factors develop in progress, and also comprise the former.

\section{FROM “ANIMATION" TO "ANIMATION FIELD”}

First, we need to interpret the core of animation creatively, or give "format" a creative outlook before we try to understand the three-stage approach. Traditional animation research would regard the animation design as a single object (though animation doesn't carry a physical form), while the animation field is to study the network featured with and centered in animation. In this paper, the animation design is regarded as a field, a progress with physical and mental interaction formed by the integration of animation products,

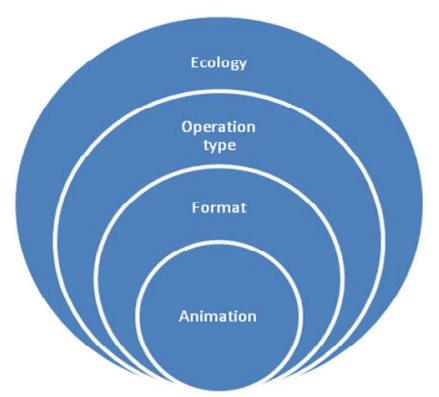


audiences and other factors. It's like an organism, a dynamic and ever-changing process. To this point, we consider "format-operation type-ecology" as three development levels of animation field.

As a media, the word "field" helps to understand the modern animation as a system rather than a single entity. The term "field" was used in physics at first. It's also used in Chinese tradition culture to help describe terms like "situation", "field perception", "qii" and so on. Some scholars have already done researches on "architecture field" and "information field" in design sciences. Putting forward the concept of animation field is a breakthrough for design subjects and forms and also changes the status of operation type design. Due to the artistry, richness and interactivity characters of animation field, the approach of "formatoperation type-ecology" fits with animation industry better than communication industry. Discussing the development pattern of "format-operation type-ecology" in terms of "animation field" will also enrich the format with novel and comprehensive contents.

\section{THE DEVELOPMENT PATTERN OF "FORMAT-OPERATION TYPE-ECOLOGY” IN ANIMATION FIELD}

\section{A. The format stage of "animation field"}

The "format" here refers to the form of presentation of things. The permutation and combination or coding system of different elements constitutes different formats. There are few researches on animation format. Existing animation format researches mainly carry on three opinions as below: A, regarding the art format of animation the same as animation creation, such as two-dimensional animation, threedimensional animation, animation with material objects; $\mathrm{B}$, referring the art format of animation to the constitution of point, line, area, space, color and time dimension; C, regarding animation art as the media of animation play, such as film animation, television animation, internet animation and cell-phone animation.

We need to talk about two questions. The first is "what is animation", namely what kind of things can be called animation. But here, we should ask "animation is what". This is the question that goes directly to the essence of animation, the distinction from other things.

The three basic relations of critic philosophy provide a good set of "natural relations" to animation format, namely, causality (function relation), separability (form relation), and internality (meaning relation) (please refer to picture 001). Philosophers think that the three relations can describe all categories of relations. Basing on above, we comb through the complicated format stage of animation field with the latter being the creation origin. With the animation field being the background, the following pictures depict relations of the field and the corresponding elements. We can see the combination of physical elements and also the mental elements in this field. Generally, it's an extension that animation develops into animation field, with the latter constituted by original part, derivative part and variation part (picture 002), or, in other way, by the image of the field itself, the object reflecting its

variation and the image of the mental part of its derivation (picture 003).

Causality

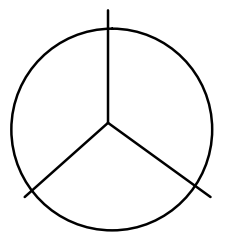

Separability Internality

Fig. 1.

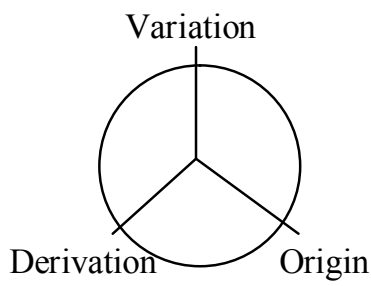

Fig.2.

Mental image (human activities, mental balances)

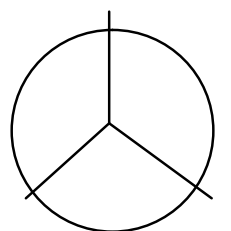

Fig.3. Object image (visible, symbol collage)

The part and the whole of the field itself 
Watching film, shopping, entertaining, communication and adaption

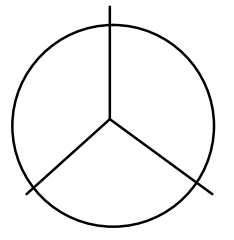

drama

animation

game

theme park

cartoon

music, voice

actor

$$
\begin{aligned}
& \text { toy, garage kit } \\
& \text { OEM products }
\end{aligned}
$$$$
\text { cosplay }
$$

OEM activities

Fig.4.

\section{B. The "operation type" stage of animation field}

The "operation type" studies the outcome of animation's adding to business. Animation as the mainstay of creation industry and culture industry always gives the market explosive power and driving force. As a result, researches on the operation type of animation are abundant. There are about 12,780 papers studied on animation industry. As a creative product, many people think that animation can be used repeatedly to develop industry values. The phrase "animation chain" is brought up frequently.

The phrase "animation chain" refers animation as a product, and the latter works with exchange rules of economics. The basis for animation chain is "attraction", and the main law is "promoting exchange". Exchange includes that of money, attention, space, site and time. Generally it is the exchange of resources. For example, the fees for entering into a cinema or enjoying a movie, or the payment you made to exchange the ownership of animation derivatives and enjoy the theme park all day long.

The economic value is also an important index to measure the success of a creative animation idea for an excellent animation field. While the development pattern of animation without "ecology" as its purpose is based on the strong stimulation power of animation creation and the direct and unlimited marketing effect of animation, which can go no far.

Well, the development pattern of "format-operation typeecology" is a creation in animation industry. Operation type becomes the link between format and ecology. The profit purpose during operation type stage represents the resources exchange ability of animation creation. A good operation type stage can help much in connecting the last stage and leading to the next.

The phrase "economic exchange" upgrades into "integration" by the development from animation to animation field. The latter is a container with much potential, in which the semiology, consumer psychology and operation laws can play roles. Operation type activates format through animation field. The sublimation of "operation type" and the integration with other resources leads to "ecology" and feed "format" back. For example, the world famous brand Disney, founded in 1923, has experienced 90 years of development and tops the world as a pioneer and classic of animation design field.

In its "format" stage, Disney applied the law of "animation format field". After gaining profit by good film products, it used the profit to invest more in creative products and extending animation forms, such as the synchronization of voice and picture, colored animation, animation with long story. More importantly, it became a good companion for people's self-mental healing and the group joy?, and the media of American traditional values.

In its "operation type" stage, Disney applied the law of "operation type of animation field". Disney achieved the sole and original creation of Disney theme park during this stage, and the collection of the film image and object image of animation. It absorbed traditional design methods and established the "animation field" that allows for audiences' entry and interaction. Audiences who love Disney animation and have sympathy with Disney value are willing to spend their time and efforts, as an exchange, to step into the real space, the object projection of virtual world, and to enjoy the splendid "animation field".

In its "ecology" stage, Disney applied the law of "animation ecology field". After developing into "operation type of animation field", it made a huge impact centered by Disney brand and possessed the ability to operate "ecology field". When Disney took over the Broadway Theater-a hasbeen, to develop its musical business in 1991, it functioned not only as an enterprise, but also a government. It injected confidence and vitality to the whole Broadway area by helping repair public facilities and strengthening public security. Many famous creation brands entered into this area as a result. Disney took the social responsibility of transforming old regions. When the transformation work was done, as the main investor, Disney developed animationthemed dramas like The Lion King, the Little Mermaid and so on and was rewarded by large success. Traditional art forms were involved into Disney animation kingdom by huge investment and the good taste of creation and became the new content of "animation format". Broadway, rejuvenated with new creations, has grown to be the center of creation resources and infused fresh blood constantly into Disney.

The ecology stage of the "animation field"

The word "ecology" carries the meaning of "green" and "environmental", also sustainable development and coexisting.

Compared with animation, the concept "animation field" surpasses the simple "stimulation-reaction" pattern between animation and audiences, inclining to the "interactioncoexisting" pattern consisted of "image" of animation, "object reflection" of animation and the "mental image" of audiences of animation, and makes the stage "ecology" available. Proposing the new purpose of "ecology animation design" extends the research of "format-operation type" and also changes the viewpoint of animation design. 
The idea of "ecology system of the field" can link animation with other systems, integrate with elements of other resources and find balance among them. The idea can lead to "design ecology" with autogous hematopoietic function and ever-lasting vitality.

Traditional animation creation and marketing are based on the "stimulation to audiences", attracting audiences to love animation films, or conducting them to love or purchase animation derivatives. The fondness caused by stimulation is easy to come and go, which is not a sincere acknowledgement and lasting memory of audiences. Lasting recognition and memory are of value depth, namely audiences love the animation from the bottom of heart. The lasting feeling is created gradually like chemical effect between audiences and films, audiences and animation images, audiences and philosophy of the animation story and goes right into the body and spirit. As a result, animation products, tangible or intangible, achieve lasting vitality through audiences. For instance, animation fans will watch the cartoons of their times with their children, take the big family to theme park with numerous pleasant memories for holidays and give their friends delicate animation themed souvenirs as presents. Animation products and brands will have partial characteristics? of living beings. It has the possibility to pass down from generation to generation and live in the heart of audiences for a very long time.

The change of expression way of animation design can bring temporary novelty. Only the animation field can bring long lasting communication function and upgrade into "ecology" stage. The "ecology" here carries the meaning of sustainable development and the "constant usage, transmission and further development" of outstanding animation creation. It can not be ditched casually like napkin. This is also can be regarded as "environment-friendly animation creation philosophy and sustainable design of animation field".

The intention of bringing up the ecology purpose of animation field is to get back to the origination of art design, namely the "interaction with human beings". To revaluing the "format" (animation art creation) and "operation type" (theory extension of industry development and enhancement of culture creation industry) in ecology dimension can give references to both new and old classic animation brand.

IV. THE SIGNIFICANCE OF RESEARCHING ON "FORMATOPERATION TYPE-ECOLOGY" PATTERN OF ANIMATION FIELD

Bringing up the term of "format-operation type-ecology" is not for fashion. More specifically, as a conclusion linked with other industry, it comes from animation development itself and, in turn, is expected to improve the development of animation.

Few researches focus on the "format-operation typeecology" pattern and animation field (as a system). Currently, overseas scholars have been sensitively aware of the systematic and ecology trend of animation design. This paper tries to research from the system aspect and creative ecology aspect of animation design. This is also a reflection of development strategy of animation design under the background of accelerating globalization and resources integration trend. I would also like to make improvements in three aspects as below: a, to improve the design method of animation format system; $b$, to promote the effective development of "operation type" stage of animation art; c, to enhance the establishment of "ecology system" of animation art.

As we know, the creation of animation art and animation technique benefits animation development. What's more, the creation on animation theory, development pattern and development approach also matters. The development pattern of "format-operation type-ecology" provides new interpretation and approach to animation design from the perspective of format, operation type and ecology. Building upon animation format, this fresh pattern is of "great animation".

\section{REFERENCES}

[1] Stephen Jia Wang. Explore the Information Fields---the Interaction Design Methodology for the Post-information Area [M]. Beijing: Tsing Hua University Press, 2011.

[2] [French] Frederic Martel. Mainstream -- Who Will Win the Global Culture War [M]. Beijing: the Commercial Press, 2012.

[3] [Russia] Mo Kagan. Art Morphology [M]. Ling Jiyao \& Jin Yana. Translator. Shanghai: Acedemic Press, 2008.

[4] [The United States]. Bob Tomas. Walt Disney---An American Original[M]. Shi Danqing. Translator. Beijing: China Machine Press, 2006 